\title{
Facilitating Students' Critical Thinking in an Inclusive Educational Environment: Model Development and Testing
}

\author{
Xiaoxia Chen \\ School of Translation Studies, Qufu Normal University, \\ Rizhao Shandong 276826, China \\ judycxxl@foxmail.com
}

\begin{abstract}
The promotion of inclusive education provides a new opportunity and research perspective for the development of critical thinking, which has gradually attracted researchers' attention. Combined with existing research results, the study constructs a model of inclusive education to promote the development of critical thinking, in which the inclusive education activities and critical thinking development elements are integrated. In order to validate the designed model, an empirical study on 90 English majors for 4 months was carried out, the results of which are presented in this paper. The results suggest that under the guidance of the social learning theory the developed model promotes the development of students' critical thinking disposition effectively. Among the related factors that influence the development of critical thinking dispositions in inclusive education, evaluation and reflection and activity task have more significant influence on the development of critical thinking.
\end{abstract}

Keywords: Critical thinking, inclusive education, learning activities, the social learning theory

\section{Introduction}

Since 1970s, the cultivation of critical thinking skills and attitudes has been established by many countries as one of the goals of higher education [1]. The training and development of critical thinking is the inevitable requirement of innovative education, which is a positive response to the challenges of the new century [2]. It promotes the all-round development of the students' quality and improves the national innovative spirit and practical ability, being of great significance to promote the construction of innovative country. Education mode and teaching method are the important factors that affect students' critical thinking cultivation. Therefore, the cultivation of critical thinking needs specialized courses, and it needs to be carried out in discipline teaching practice as well [3]. With the popularization of inclusive education, it is becoming more and more important to develop the students' cognitive ability and thinking ability. As a new educational concept, inclusive education is not only related to the theory and method of education, but also to the re-understanding and evaluation of the value of human being in the society [4].

Effective teaching activities, the core of inclusive education, can clearly reproduce the students' knowledge construction, cognitive development and the formation process of thinking. Effective teaching activities from the perspective of inclusive education expand the depth and breadth of interaction among students, and it can also promote the development of critical thinking ability, such as argumentation, evaluation and reflection [5]. Positive interaction, dialogue-based learning and problem-based learning are the powerful pedagogical approaches and an aligned teaching and learning systems to

Received (December 13, 2017), Review Result (February 28, 2018), Accepted (March 4, 2018) 
explicitly and directly promote critical thinking. It is very important for the students to improve their critical thinking ability through the effective teaching activities under the paradigm of inclusive education. From the viewpoint of structuralism, effective teaching activity is a subsystem of the whole inclusive education. Therefore, the implementation of effective teaching activities is not simply a problem of classroom teaching; it involves all aspects of inclusive education. Effective teaching activities from the perspective of inclusive education provide an effective way for the cultivation of students' critical thinking.

Therefore, constructing the inclusive education model based on the social learning theory provides a new perspective for the study of inclusive education, which also has important research significance for critical thinking. On the basis of the social learning theory, this study constructs an inclusive education model to promote the development of critical thinking, mainly using qualitative and quantitative methods. It aims to validate the effect of inclusive education activities on the development of college students' critical thinking, and study the relationship between effective inclusive education activities and critical thinking. Then, the study will be of benefit to better design and control effective teaching activities and promote students' critical thinking.

The rest of the paper includes the following sections: Section 2 discusses the related previous research in inclusive education, critical thinking and the social learning theory. Section 3 illustrates the research design. The discussions about the research results are elaborated in Section 4. A conclusion in Section 5 concludes the paper.

\section{Literature Review}

Critical thinking under that name was inspired by pragmatic philosopher John Dewey and endorsed by analytic philosopher Max Black. Traditionally, it has been variously defined. Critical thinking is a normative enterprise in which, to a greater or lesser degree, we apply appropriate criteria and standards to what we or others say, do, or write [6]. Critical thinking includes a commitment to using reason in the formulation of our beliefs [7]. Facione [8] defines critical thinking as purposeful, self-regulatory judgment which results in interpretation, analysis, evaluation, and inference, as well as explanation of the evidential, conceptual, methodological, or contextual considerations upon which that judgment is based. Contemporary critical thinking scholars have expanded these traditional definitions to include qualities, concepts, and processes such as creativity, imagination, discovery, reflection, empathy, connecting knowing, feminist theory, subjectivity, ambiguity, and inconclusiveness [9]. Although the definitions are different, they all involve the nature of critical thinking.

It's generally accepted there are two dimensions of critical thinking: critical thinking skills and critical thinking dispositions. Critical thinking skills are the basic method to analyze the problem [10]. Critical thinking dispositions, also known as critical thinking temperament and critical thinking essence, are the mental preparation, intention and inclination of conscious critical thinking [11]. There are seven scales of critical thinking dispositions: truthseeking, open-mindedness, analyticity, systematicity, confidence in reasoning, inquisitiveness and maturity of judgmen [12]. Critical thinking dispositions are the internal motive force of the development of critical thinking. Cultivating students' willingness to use critical thinking ability is the premise of improving critical thinking ability. In 1990s, the United States, Britain and other countries have applied critical thinking education in different stages of the education system. Improving the way of education, teaching content and evaluation methods are the effective ways to promote the development of critical thinking [13].

Inclusive education has a history of over 20 years, but there is no unified definition yet. Originally, inclusion in education is an approach to educating students with special educational needs, and inclusive education is viewed as a category of special education 
[14]. Tony breaks through this narrow vision. He thinks inclusive education means that all students attend and are welcomed by their neighborhood schools in age-appropriate, regular classes and are supported to learn, contribute and participate in all aspects of the life of the school [15]. Inclusive education differs from the 'integration' or 'mainstreaming' model of education. By contrast, inclusion is about the students' right to participate and the school's duty to accept all children. Inclusive education not only develops individual strengths and gifts, but also fosters a school culture of respect and belonging and positively affects both schools and communities to appreciate diversity and inclusion on a broader level [1].

Social learning theory is a theory of learning and social behavior which proposes that new behaviors can be acquired by observing and imitating others, which states that learning is a cognitive process that takes place in a social context and can occur purely through observation or direct instruction, even in the absence of motor reproduction or direct reinforcement [16]. Aiming to provide a comprehensive model that could account for the wide range of learning experiences occurring in the real world, it integrates behavioral and cognitive theories of learning. Therefore, it is a category of learning theories which is grounded in the belief that human behavior is determined by a three-way relationship between cognitive factors, environmental influences and behavior [17]. As initially outlined and further detailed by Bandura and Walters, learning involves observation, extraction of information from those observations, and making decisions about the performance of their behavior [18]. Many classroom teaching strategies draw on principles of social learning theory to enhance students' knowledge acquisition and retention [19].

The aforementioned research has mainly focused on the role and influence, strategy and methods of critical thinking and inclusive education separately, but little is known about the combination of critical thinking and inclusive education. Therefore, starting from the perspective of effective inclusive education activities, this study will construct an inclusive education model to promote the development of critical thinking, and demonstrate its positive influence on the development of students' critical thinking empirically. Basing on the social learning theory, it will be an important contribution to facilitating students' critical thinking and implementing inclusion in education effectively.

\section{Research Design}

\subsection{Inclusive Education Model to Promote the Development of Critical Thinking}

Based on the social learning theory, this study constructs an inclusive education model to promote the development of critical thinking from two aspects: effective inclusive education activities design and critical thinking disposition. As a theory of learning and social behavior which proposes that new behaviors can be acquired by observing and imitating others, the social learning theory emphasizes the role of observation learning and self-regulation in the initiation of human behavior and the interaction between human behavior and environment [20]. Therefore, facilitating students' critical thinking in inclusive education is not simply the change of teaching methods. The influence of the teaching situation, learning needs, learning group, the allocation of learning activities, the type of interactive activities, evaluation and reflection on the development of critical thinking should be considered fully. In this study, effective inclusive education activities include four levels: individual inquiry, social interaction, critical learning and reflective learning. Accordingly, activities are divided into four categories: guiding activities, interactive activities, constructive activities, and reflective activities, including 14 specific activity contents, as shown in Table 1 . In the learning process, students gradually improve their truthseeking, open-mindedness, analyticity, systematicity, confidence in reasoning, inquisitiveness and maturity of judgment, ultimately facilitating their critical thinking 
skills.

Table 1. Effective Activities in Inclusive Education

\begin{tabular}{|c|c|c|}
\hline Activity levels & Activity categories & Activity contents \\
\hline \multirow{3}{*}{ Individual inquiry } & \multirow{3}{*}{ Guiding activities } & Specifying themes \\
\hline & & Literature review \\
\hline & & Critical reading \\
\hline \multirow{5}{*}{ Social interaction } & \multirow{5}{*}{ Interactive activities } & Information sharing \\
\hline & & Brainstorming \\
\hline & & Role-play \\
\hline & & Debates \\
\hline & & Seminars \\
\hline \multirow{3}{*}{ Critical learning } & \multirow{3}{*}{ Constructive activities } & Heterogeneous grouping \\
\hline & & Critical questioning \\
\hline & & Personal comments \\
\hline \multirow{3}{*}{ Reflective learning } & \multirow{3}{*}{ Reflective activities } & Homework \\
\hline & & Assessment \\
\hline & & Reflection \\
\hline
\end{tabular}

The interaction of all factors in inclusive education is linked by effective activities. In this study, the related factors that influence the development of critical thinking dispositions in inclusive education are summarized into the following eight: learning situation, learning resources, teacher guidance, learning style, problem guidance, activity task, role division, and evaluation and reflection. According to the conceptual model for developing critical thinking [21], this study attempts to construct a cross-level inclusive education model from the perspective of the social learning theory, aiming at explaining the basic characteristics and evolution mechanism of the model and promoting the development of critical thinking. As shown in Figure 1, the model is dynamic and cross-level which includes four levels (individual inquiry, social interaction, critical learning and reflective learning) and four links (guiding activities, interactive activities, constructive activities, and reflective activities). The model is based on the activities of inclusive education which are centering on seven dimensions of critical thinking. The progressive process of the four kinds of activities can be seen as a gradual process from individual inquiry to reflective learning. In the iteration process, students' critical thinking is in spiral promotion. 


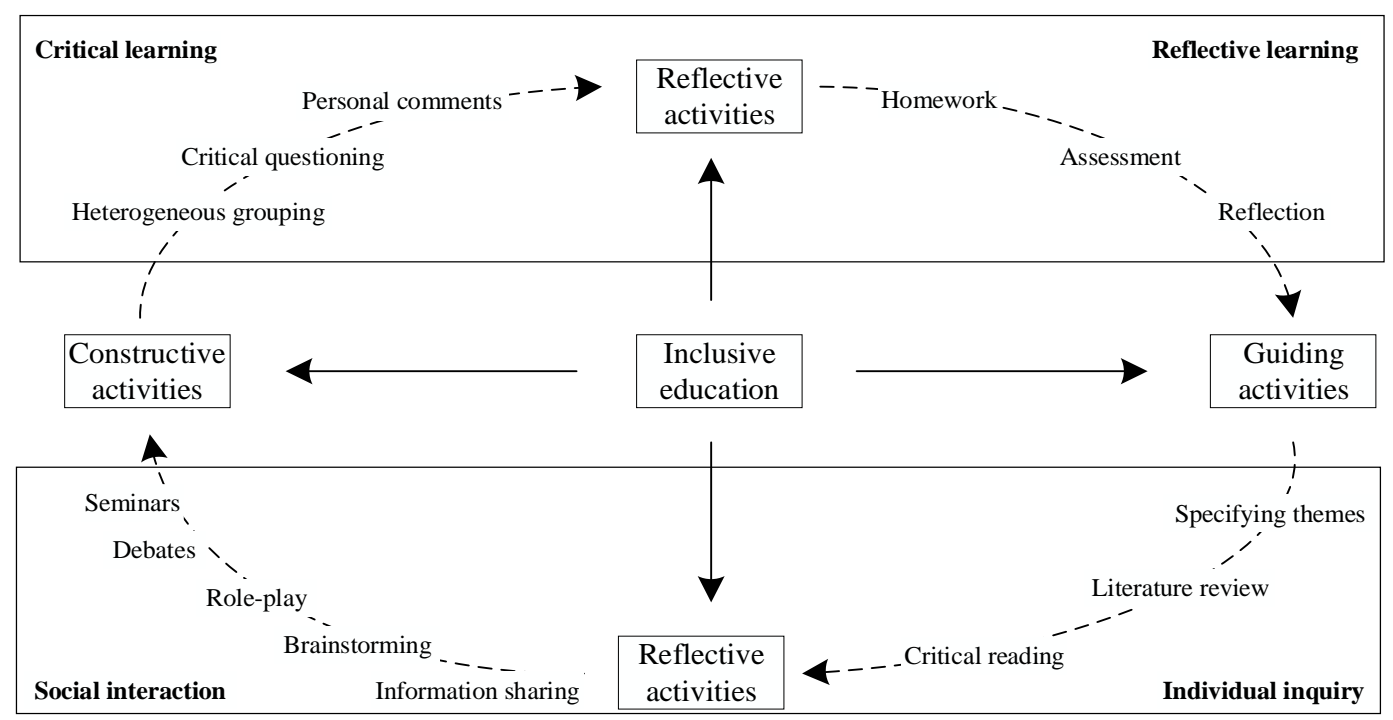

\section{Figure 1. Inclusive Education Model to Promote the Development of Critical Thinking}

Individual inquiry is the first stage. There are mainly guiding activities designed according to teaching situations and themes, such as specifying themes, literature review and critical reading, etc. Individual inquiry is the initial stage of inclusive education in this model, mainly cultivating students' truth-seeking, open-mindedness, objective attitude towards knowledge and tolerant attitude towards different opinions.

Social interaction is the process of cognitive conflict, debate and negotiation of common knowledge among group members and members out of the group. Interactive activities, such as information sharing, brainstorming, role play, debates, and seminars are mainly designed according to relevant task situation and problem guidance. These interactive activities are the social interaction among students and learning contents and peers. Because of the cognitive conflict, the students will make a deep analysis, inference and problem solving, then their analyticity, systematicity, and inquisitiveness will be cultivated.

Critical learning is the core stage, and the main activities are constructive activities. The weak control of inclusive education requires that the learning activities must set up corresponding monitoring management throughout the whole stage. Constructive activities include heterogeneous grouping, critical questioning, personal comments and so on.

Reflective learning is the advanced stage of the knowledge construction of students and learning communities, in which reflective activities are mainly designed, such as homework, assessment and reflection, etc. The degree of students reflection is related to the higher-order thinking ability. Therefore, students are able to make judgments on their own and others' opinions, and adopt a variety of ways to solve problems gradually, and their maturity of judgment will be facilitated gradually.

\subsection{Research Participants}

The participants involved in this study are two intact classes of 2015 in School of Translation Studies of Qufu Normal University, which are chosen randomly by the author. There are totally 46 students in class 1 (38 female students, 8 male students) and totally 44 students in class 1 (34 female students, 10 male students). To validate the effectiveness of the designed model, an empirical study on 90 English majors for 4 months was carried out. 


\subsection{Research Instruments}

\subsubsection{Questionnaire}

Based on literature research and focus group, a questionnaire of influence factors of critical thinking dispositions in inclusive education activities is designed, aiming at investigating the correlation between inclusive education activities and the development of critical thinking. Before large-scale questionnaire survey, 20 questionnaires were randomly distributed to conduct a pre-survey in order to ensure the rationality and feasibility of the questionnaire. According to the results of the pre-survey, the Likert five-scale questionnaire was revised, which consists of eight independent variables: learning situation, learning resources, teacher guidance, learning style, problem guidance, activity task, role division, and evaluation and reflection. Evaluation of each variable has five scales: very large effect, relatively large effect, the general effect, very small effect and no effect. The internal consistency reliability analysis indicated that Cronbach's Alpha of the scale is 0.785 , meaning that the questionnaire design has high reliability. Finally, 90 questionnaires were given out and 85 valid questionnaires were collected back, with the effective response rate of $94 \%$.

\subsubsection{Test}

In this study, California Critical Thinking Disposition Inventory (CCTDI) is used to conduct the pre-test and post-test separately. CCTDI designed for use of the general adult population, is the premier tool for surveying the dispositional aspects of critical thinking, measuring the disposition to engage problems and make decisions using critical thinking [22]. There are seven scales of CCTDI: truth-seeking, open-mindedness, analyticity, systematicity, confidence in reasoning, inquisitiveness and maturity of judgment [23]. The CCTDI uses a 6 -point Likert scale in which $1=$ strongly agree and $6=$ strongly disagree. Each scale score describes an aspect of the overall disposition toward using one's critical thinking to form judgments about what to believe or what to do [24]. Each disposition has 10 items, having the score from 10 to 60 points. For each disposition, total score less than 30 points indicates negative attitude, and above 40, positive attitude. Total CCTDI score of 280 points or less indicates serious deficiency in critical thinking deposition; total CCTDI score between 280 and 350 indicates ambivalent attitude; and total CCTDI score above 350 is consistent with a solid indication of strength in the disposition toward critical thinking [22]. 90 CCTDI measurement scales were given out and 85 valid scales were collected back, with the effective response rate of $94 \%$. Cronbach's value of the scale was higher than 0.778 , which means the scale had good reliability and validity.

\subsubsection{Data Processing Technique}

In this study, SPSS20.0 is used to conduct descriptive statistics, paired-samples t test and correlation analysis, in order to validate the empirical results of the inclusive education model to promote the development of critical thinking. Descriptive statistics are applied to get the overall situation of the critical thinking disposition of the pre-test and post-test. Paired-samples t test is applied to test whether there are significant differences in participants' critical thinking before and after inclusive education activities. With the method of multiple linear regression, the study analyzes the questionnaire of influence factors of critical thinking dispositions in inclusive education activities.

\subsection{Research Process}

Relying on the teaching platform of School of Translation Studies of Qufu Normal University, the designed inclusive education model is implemented and applied in Integrated English Course. According to the teaching arrangement, inclusive education 
learning contents are divided into 10 modules, with guiding activities, interactive activities, constructive activities, and reflective activities for each module. Students study 10 modules for a semester of 4 months. The learning process is 10 cycles of the implementation of the designed inclusive education model. The research process is shown in Figure 2.

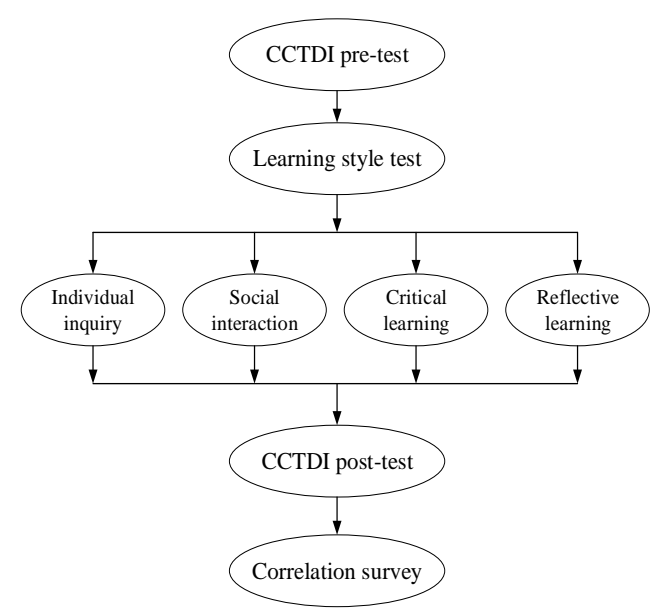

Figure 2. The Research Process

\section{Analysis of Results}

\subsection{Subscale Analysis of the Pre-test and Post-test of Students' Critical Thinking Disposition}

As shown in Table 2, for truth-seeking, open-mindedness, analyticity, systematicity, confidence in reasoning, and inquisitiveness, the mean value of the post-tests has been improved 0.5-2 points, compared with those of the pre-tests; the mean value of maturity of judgment decreases 2 points. The paired-samples study for the 7 critical thinking dispositions in pre-test and post-test ( Table 3 ) shows that for pair $3, \mathrm{t}=-3.561, \mathrm{p}=0.002$ $\leqslant .05, \mathrm{df}=79$; for pair $4, \mathrm{t}=-2.037, \mathrm{p}=0.041 \leqslant .05, \mathrm{df}=79$; for pair $6, \mathrm{t}=-1.431, \mathrm{p}=0.012$ $\leqslant .05, \mathrm{df}=79$; for pair $7, \mathrm{t}=-2.185, \mathrm{p}=0.041 \leqslant .05 \mathrm{df}=79$. Therefore, the paired-samples $\mathrm{t}$ test shows that there is correlation between pre-test and post-test of each subscale and inclusive education activities have a certain influence to facilitate students' critical thinking. The differences of the mean value between the pre-test and the post-test for analyticity, systematicity, inquisitiveness and maturity of judgment are significant, showing that students' promotion in these 4 dimensions is obvious.

Table 2. Descriptive Statistics of the Subscales

\begin{tabular}{c|c|c|c|c|c|c}
\hline \multirow{2}{*}{ Subscale } & Test & N & $\begin{array}{c}\text { Minimum } \\
\text { value }\end{array}$ & $\begin{array}{c}\text { Maximum } \\
\text { value }\end{array}$ & $\begin{array}{c}\text { Mean } \\
\text { value }\end{array}$ & $\begin{array}{c}\text { Standard } \\
\text { deviation }\end{array}$ \\
\hline \multirow{2}{*}{ Truth seeking } & Pre-test & 85 & 24 & 52 & 38.07 & 5.246 \\
\cline { 2 - 7 } & Post-test & 85 & 21 & 57 & 38.59 & 6.121 \\
\hline \multirow{2}{*}{ Open-mindedness } & Pre-test & 85 & 30 & 55 & 44.09 & 4.765 \\
\cline { 2 - 7 } & Post-test & 85 & 31 & 53 & 43.60 & 4.143 \\
\hline
\end{tabular}




\begin{tabular}{c|c|c|c|c|c|c}
\hline \multirow{4}{*}{ Analyticity } & Pre-test & 85 & 27 & 52 & 42.03 & 4.065 \\
\cline { 2 - 7 } & Post-test & 85 & 34 & 60 & 44.12 & 4.603 \\
\hline \multirow{3}{*}{ Systematicity } & Pre-test & 85 & 25 & 52 & 41.53 & 5.341 \\
\cline { 2 - 7 } & Post-test & 85 & 30 & 56 & 42.84 & 4.137 \\
\hline $\begin{array}{c}\text { Confidence in } \\
\text { reasoning }\end{array}$ & Pre-test & 85 & 21 & 48 & 34.52 & 4.615 \\
\cline { 2 - 7 } \begin{tabular}{c} 
Inquisitiveness \\
\cline { 2 - 7 }
\end{tabular} & Post-test & 85 & 28 & 49 & 34.17 & 4.208 \\
\cline { 2 - 7 } & Pre-test & 85 & 34 & 55 & 43.57 & 4.354 \\
\hline \multirow{2}{*}{\begin{tabular}{c} 
Maturity of judgment \\
\cline { 2 - 7 }
\end{tabular}} & Pre-test & 85 & 30 & 52 & 41.55 & 4.805 \\
\cline { 2 - 7 } & Post-test & 85 & 23 & 53 & 39.54 & 5.907 \\
\hline
\end{tabular}

Table 3. Paired-sample t Test of the Subscale

\begin{tabular}{l|c|c|c|c|c|c}
\hline & Mean & $\begin{array}{c}\text { Std. } \\
\text { deviation }\end{array}$ & $\mathbf{t}$ & df & sig (2-tailed) \\
\hline Pair 1 & T1-T2 & -.501 & 4.881 & -.901 & 79 & 0.253 \\
\hline Pair 2 & O1-O2 & -.563 & 4.335 & -1.023 & 79 & 0.221 \\
\hline Pair 3 & A1-A2 & -1.500 & 3.974 & -3.561 & 79 & 0.002 \\
\hline Pair 4 & S1-S2 & -1.321 & 4.853 & -2.307 & 79 & 0.041 \\
\hline Pair 5 & C1-C2 & -.867 & 4.575 & -1.867 & 79 & 0.068 \\
\hline Pair 6 & I1-I2 & -1.047 & 5.663 & -1.431 & 79 & 0.012 \\
\hline Pair 7 & M1-M2 & 1.402 & 5.973 & -2.185 & 79 & 0.041 \\
\hline
\end{tabular}

\subsection{Total CCTDI Score Analysis of the Pre-test and Post-test}

As shown in the Table 4, the highest score of the pre-test is 320 points, the lowest, 221 points; and the highest score of the post-test is 358 points, the lowest, 253 points. The mean values of the pre-test and post-test are 280.71 points and 285.83 points, which means the overall improvement in students' critical thinking. The frequencies of the total score of above 300 points in the pre-test and post-test are $11.5 \%$ and $20.5 \%$. The skewness coefficients for the pre-test and post-test are $0.372(<1)$ and $0.453(<1)$. All of these shows normal distribution of the total score of the pre-test and post-test. The standard deviation shows that the discrete degree of the pre-test scores is lower than that of the post-test. Therefore, the total scores of the pre-test and post-test are different, which is statistically significant. 
Table 4. Descriptive Statistics of Total CCTDI Score Analysis of the pre-test and post-test

\begin{tabular}{c|c|c|c|c|c|c|c}
\hline & $\mathbf{N}$ & $\begin{array}{c}\text { Minimum } \\
\text { value }\end{array}$ & $\begin{array}{c}\text { Maximum } \\
\text { value }\end{array}$ & $\begin{array}{c}\text { Mean } \\
\text { value }\end{array}$ & $\begin{array}{c}\text { Standard } \\
\text { deviation }\end{array}$ & Variance & Skewness \\
\hline $\begin{array}{c}\text { Total } \\
\text { score of } \\
\text { pre-test }\end{array}$ & 85 & 221 & 320 & 280.71 & 18.612 & 346.763 & -.372 \\
\hline $\begin{array}{c}\text { Total } \\
\text { score of } \\
\text { post-test }\end{array}$ & 85 & 253 & 358 & 285.83 & 21.357 & 442.817 & .453 \\
\hline
\end{tabular}

The results of paired-samples $t$ test (Table 5) indicate the t-value to be -2.106. Based on the size of the sample, the value is significant at the .032 level. The author reports the results as: $\mathrm{t}=-2.106 ; \mathrm{p}=0.032 \leqslant .05$, and therefore draws the conclusion that the difference between the total scores of the pre-test and post-test is significant, rejecting null hypothesis. That means inclusive education activities have a positive effect on the development of students' critical thinking.

Table 5. Paired-samples $t$ Test of the Total Score of pre-test and post-test

\begin{tabular}{c|c|c|c|c}
\hline & & t & df & sig (2-tailed) \\
\hline Pair 1 & $\begin{array}{c}\text { Total score of pre-test-— } \\
\text { Total score of post-test }\end{array}$ & -2.106 & 79 & .032 \\
\hline
\end{tabular}

\subsection{Correlation Analysis}

Analysis results of multiple linear regression (Table 6) suggest that after 2 times of regression analysis evaluation and reflection $(\beta=0.274, \mathrm{t}=2.479, \mathrm{p}=0.001)$ and activity task $(\beta=0.257, \mathrm{t}=2.337, \mathrm{p}=0.002<0.005)$ are more prominent in the designed model and are extracted. The regression equation that critical thinking disposition can be predicted by evaluation and reflection and activity task is: critical thinking disposition $=254.157+5.789 \times$ evaluation and reflection $+4.732 \times$ activity task. The result shows evaluation and reflection and activity task can predict the post-test scores of critical thinking disposition, which have a higher correlation with critical thinking disposition. After four months of inclusive education activities, the participants of the study think that interactive tasks and evaluation and reflective activities have a strong influence on their critical thinking.

Table 6. Analysis Results of Multiple Linear Regression

\begin{tabular}{c|c|c|c|c|c}
\hline \multirow{2}{*}{ Model } & \multicolumn{2}{|c|}{ Unstandardized coefficients } & $\begin{array}{c}\text { Standardized } \\
\text { coefficients }\end{array}$ & \multirow{2}{*}{$\mathbf{t}$} & \multirow{2}{*}{ Sig } \\
\cline { 2 - 5 } & $\mathbf{B}$ & Std. error & Beta & & \\
\hline Constant & 254.157 & 8.104 & & 31.897 & 0.000 \\
\hline $\begin{array}{c}\text { Evaluation } \\
\text { \& reflection }\end{array}$ & 5.789 & 2.203 & 0.274 & 2.479 & 0.001 \\
\hline Activity task & 4.732 & 2.135 & 0.257 & 2.337 & 0.002 \\
\hline
\end{tabular}




\section{Conclusion}

From the perspective of inclusive education activities design, this study combines inclusive education and the cultivation of critical thinking, aiming at facilitating students' critical thinking disposition. Based on the social learning theory, an inclusive education model to promote the development of critical thinking is constructed, and validated empirically. The model is a dynamic system, containing four levels (individual inquiry, social interaction, critical learning and reflective learning) and four kinds of activities (guiding activities, interactive activities, constructive activities, and reflective activities). It can effectively guide the design of classroom teaching activities, and guarantee the effectiveness of learning activities design. At the same time, the model is beneficial to establish the coordination relationship among internal factors of learning activities, and effectively promote the development of students' critical thinking.

Firstly, the significant difference of total scores between the pre-test and post-test verifies the effectiveness of the designed model in the development of critical thinking. The results of empirical analysis indicate that the overall mean value of the students' critical thinking disposition has been improved after four months of study. The weak degree of critical thinking disposition tends to decline from $46.2 \%$ to $41 \%$; the neutral degree increases from $53.8 \%$ to $57.7 \%$; and the stronger degree increases to $1.3 \%$. Generally speaking, the students' critical thinking disposition moves toward the neutral and the stronger regions. The comparison of the the standard deviation and variance data of the pre-test and post-test indicates the total score of the post-test is more dispersed than that of pre-test and the gap between the high and low points is widening. The improvement of analyticity, systematicity, inquisitiveness and maturity of judgment in subscales is more significant, and the number of students with a stronger open-mindedness and inquisitiveness has increased, which proves the designed model of inclusive education really facilitates the development of critical thinking.

Furthermore, systematic and externalized education activities are related to internalized thinking activity. Compared with the other six factors that influence the development of critical thinking dispositions in inclusive education, activity task and evaluation and reflection have higher correlations with critical thinking disposition. Students' critical thinking and critical discussion about information is shown in effective social interaction, which is the interconversion between internalization and externalization. Therefore, how to set up effective interaction has become the key link of improving students' critical thinking in the inclusive teaching process. In inclusive teaching activity design, attention should be paid to the role of social interaction and reflective learning, and a variety of educational activities to promote students' critical thinking disposition of each dimension should be applied.

Finally, there are still some deficiencies in this study owning to the limited data sources and complex research process, although the model can provide theoretical and empirical basis for the follow-up study. In the following research, the scope and level of sample selection should be expanded to enhance the universality of the designed inclusive education model. Moreover, a valuable next step would be to conduct further research on the learning activities experienced by different types of learners and coordinating the relationships between the elements in four interactive phases. Taking into account the factors affecting interactive activities in inclusive education, the designed model should be modified further to improve interaction effects and quality, and enhance students' cognitive level, reflective ability and critical ability ultimately.

Research like this will shed light on very important issues in inclusive education and help students facilitate their critical thinking.

\section{Acknowledgments}

This work was supported by MOE (Ministry of Education in China) Project of 
Humanities and Social Sciences under Grant [No. 17YJCZH026]; the Social Science Research Project of Shandong Higher Education Institutions under Grant [No. J17RA044]; Philosophy and Social Science Research Program of Qufu Normal University under Grant [No. XSK201618].

\section{References}

[1] D. Armstrong, "Educator perceptions of children who present with social, emotional and behavioural difficulties: A literature review with implications for recent educational policy in England and internationally", International Journal of Inclusive Education, vol. 18, no. 7, (2014), pp. 731-745.

[2] A. Fisher, "Critical Thinking. An Introduction", Cambridge University Press, Cambridge, (2011).

[3] R. Kennedy, "In-Class Debates: Fertile Ground for Active Learning and the Cultivation of Critical Thinking and Oral Communication Skills", International Journal of Teaching \& Learning in Higher Education, vol. 19, no. 2, (2007), pp. 183-190.

[4] G. Lindsay, "Inclusive education: a critical perspective", British Journal of Special Education, vol. 18, no. 30, (2003), pp. 3-12.

[5] L. W. Smith and D. C. Van Doren, "The reality-based learning method: a simple method for keeping teaching activities relevant and effective", Journal of Marketing Education, vol. 26, no. 26, (2004), pp. 66-74.

[6] B. Sharon, C. Roland, R. C. Jerrold and B. D. Leroi, "Conceptualizing critical thinking", Journal of Curriculum Studies, vol. 31, no. 3, (1999), pp. 285-302.

[7] J. W. Mulnix, "Thinking critically about critical thinking", Educational Philosophy and Theory, vol. 44, no. 5, (2012), pp. 464-479.

[8] P. A. Facione, "Critical thinking: what it is and why it counts", California Academic Press, Millbrae, (2015).

[9] K. S. Walters, "Re-thinking reason: new perspectives in critical thinking", State University of New York Press, New York, (1994).

[10] S. Cottrell, "Critical thinking skills: developing effective analysis and argument", Palgrave Macmillan, New York, (2011).

[11] S. Emir, "Contributions of teachers' thinking styles to critical thinking dispositions (istanbul-fatih sample)", Educational Sciences Theory \& Practice, vol. 13, (2013), pp. 337-347.

[12] S. Wangensteen, I. S. Johansson, M. E. Björkström and G. Nordström, "Critical thinking dispositions among newly graduated nurses”, Journal of Advanced Nursing, vol. 66, no. 10, (2010), pp. 2170-2181.

[13] A. I. Mwalongo, "Using Activity Theory to Understand Student Teacher Perceptions of Effective Ways for Promoting Critical Thinking through Asynchronous Discussion Forums", SensePublishers, Rotterdam, (2016).

[14] M. Kalyanpur, "Inclusive Education: International policy and practice", International Journal of Disability, Development and Education, vol. 58, no. 1, (2011), pp. 98-100.

[15] B. Tony, A. Mel and D. Alan, "Understanding inclusion and exclusion in the English competitive education system", International Journal of Inclusive Education, vol. 1, no. 4, (1997), pp. 337-355.

[16] A. Bandura, "Social learning theory", Journal of Organizational Behavior Management, vol. 3, no. 4, (1977), pp. 55-63.

[17] P. S. Henry and C. M. Charles, "Social Learning Theory", Journal of Organizational Behavior Management, vol. 7, no. 4, (1981), pp. 84.

[18] R. J. Varey, "Social Learning Theory", John Wiley \& Sons, Ltd, Hoboken, (2015)

[19] K. Kumpulainen and D. Wray, "Classroom interaction and social learning: from theory to practice", RoutledgeFalmer, New York, (2002).

[20] C. P. Travis, T. C. Francis, S. S. Christine, L. Thomas, D. M, Tamara and E. D. Leah, "The Empirical Status of Social Learning Theory: A Meta-Analysis", Justice Quarterly, vol. 27, no. 6, (2010), pp. 765-802.

[21] D. R. Garrison, "Critical thinking and adult education: a conceptual model for developing critical thinking in adult learners", International Journal of Lifelong Education, vol. 10, no. 4, (2006), pp. 287-303.

[22] S. Iranfar, "Validly and reliability of california critical thinking disposition inventory (cctdi) in kermanshah university of medical sciences", Clinical Practice \& Epidemiology in Mental Health, vol. 8, no. 1, (2012), pp. 22-29.

[23] G. Iskifoglu, "Cross-Cultural Equivalency of the California Critical Thinking Disposition Inventory", Educational Sciences Theory \& Practice, vol. 14, no. 1, (2014), pp.1-20.

[24] N. C. Facione, "The california critical thinking disposition inventory (cctdi)", California Academic Press, Millbrae, (1992). 


\section{Author}

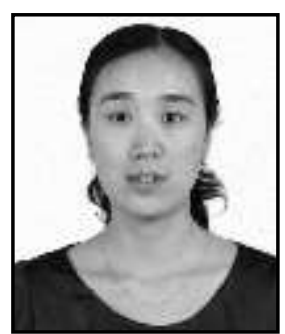

Xiaoxia Chen, born in 1979, is now a lecturer of School of Translation Studies, Qufu Normal University. She obtained her bachelor's degree of English education from Qufu Normal University in 2002, and master's degree of applied linguistics from Qufu Normal University in 2005. She has published more than 20 papers. Her major research interests include language teaching and higher education. 